\title{
Myelin Basic Protein Gene Expression in Neurons: Developmental and Regional Changes in Protein Targeting within Neuronal Nuclei, Cell Bodies, and Processes
}

\author{
Charles F. Landry, Julie A. Ellison, Thomas M. Pribyl, Celia Campagnoni, Kathy Kampf, \\ and Anthony T. Campagnoni \\ Mental Retardation Research Center, Neuropsychiatric Institute, University of California at Los Angeles School of \\ Medicino, Los Angeles, California 90024
}

\begin{abstract}
The myelin basic protein (MBP) gene is part of the golli-mbp gene complex. In mouse, the golli-mbp gene produces two families of mRNAs from different transcription start sites that generate either MBPs or golli proteins (which contain MBP sequences in addition to unique peptide sequences). In situ hybridization and immunocytochemical analyses indicate that golli products are expressed in selected neuronal populations in postnatal mouse brain, in addition to oligodendrocytes, as shown earlier. The principal subcellular location of golli proteins in neurons was in axonal and dendritic processes. In a small subset of neurons, golli proteins were located in nuclei. With development and neuronal maturation, golli-mbp expression decreased and/or there was a striking shift in subcellular localization from nuclei and cell soma to the cell processes in specific neuronal populations. Golli protein was localized in
\end{abstract}

Myelin basic protein (MBP) is an integral component of CNS myelin and begins to be expressed during the terminal differentiation of oligodendrocytes (Campagnoni and Macklin, 1988). In mouse, the MBP transcription unit consists of eight exons that are alternatively spliced to produce at least eight Iranscripts (de Ferra et al., 1985; Takahashi et al., 1985; Newman et al., 1987; Kitamura et al., 1990; Aruga et al., 1991). The major alternatively spliced MBP mRNAs encode MBP isoforms that range in molecular mass from 14 to $21 \mathrm{kDa}$ (Roth et al., 1987; Kamholz et al., 1988). An additional transcript, called M41-MBP mRNA, is produced from a second, minor transcription start site that lies 32 kilobases $(\mathrm{kb})$ upstream of the major MBP transcription start site and encodes a 14 kDa MBP (Kitamura et al., 1990).

The MBP genc has recently been found to be part of a larger gene complex called Golli (for gene expressed in the oligodendrocyte lineage)-mbp because initial studies showed the golli mRNAs were expressed in oligodendrocytes (Campagnoni et al., 1993). The golli transcription unit consists of 11 exons, 7 of which encode the classical MBPs, one which contains $5^{\prime}$-untranslated sequence unique to M41-MBP, and three that define the $5^{\prime}$ sequences of the recently characterized golli transcripts. The murine golli promoter lies $\sim 70 \mathrm{~kb}$ upstream from the classical

\footnotetext{
Received Sept. 15, 1995; revised Jan. 16, 1996; accepted Jan. 22, 1996.

This work was supported in part by National Institutes of Health Grants NS23022, NS23322, NS33091, and Multiple Sclerosis Society of America Grant RG2233A1.

Correspondence should be addressed to Dr. Anthony T. Campagnoni, MRRC/ NPI, 47-448, UCLA School of Medicine, 760 Westwood Plaza, Los Angeles, CA 90024.

Copyright (C) 1996 Society for Neuroscience $0270-6474 / 96 / 162452-11 \$ 05.00 / 0$
}

neurites of migrating cerebellar granule cells, but it shifted to a nuclear localization when the cells took up residence in the internal granule cell layer. In some regions, (e.g., olfactory bulb and cerebellum) golli proteins were expressed over the entire postnatal period examined (birth to $75 \mathrm{~d}$ ).

The unique patterns of developmental expression within individual populations of neurons, and the unusual shift in subcellular localization of golli proteins with neuronal migration and maturation, suggest a complex regulation of this gene at both the transcriptional and posttranslational levels. The data also suggest that the cellular function(s) of the golli proteins is very different from the structurally related MBPs.

Key words: golli-mbp; neuronal development; immunocytochemistry; in situ hybridization; protein targeting; nuclear localization
MBP gene and produces three major transcripts that contain, by alternative splicing, MBP exons at their $3^{\prime}$ ends. Northern blots of postnatal mouse brain have identified a major mRNA species of $5.1 \mathrm{~kb}$ (BG21), a less prominent species of $2.6 \mathrm{~kb}(\mathrm{~J} 37)$, and a minor species of $2.3 \mathrm{~kb}$ (TP8; Campagnoni et al., 1993). The predicted proteins encoded by two of these transcripts (BG21 and J37) contain MBP polypeptide sequences within their C-terminal halves. The non-MBP portions of these molecules do not show similarity to any characterized protein, and the function of golli proteins is not yet known.

The promoters that drive the two major transcription start sites within the golli-mbp gene complex are regulated differently both during development and within specific tissues (Campagnoni et al., 1993; Pribyl et al., 1993). Transcripts produced from the classical MBP promoter are confined to myelin forming cells and in the CNS are restricted to oligodendrocytes in the later stages of maturation (Trapp et al., 1987; Verity and Campagnoni, 1988). MBP promoter sequences extending $1.3 \mathrm{~kb}$ upstream from the MBP transcription start site are sufficient to drive the expression of MBP or reporter gene constructs with appropriate developmental and cell specificity (Kimura ct al., 1989; Miskimins ct al., 1992). Furthermore, the MBP gene has been introduced into shiverer (shi) mutant mice (which contain a deletion of golli-mbp exons 7-11) with a subsequent reduction in the clinical signs of the neurological disorder caused by the mutation (Readhead et al., 1987).

To begin to understand the regulation and expression of this complex gene, we have analyzed the regional and cellular expression of golli protein and mRNA using immunocytochemistry and 

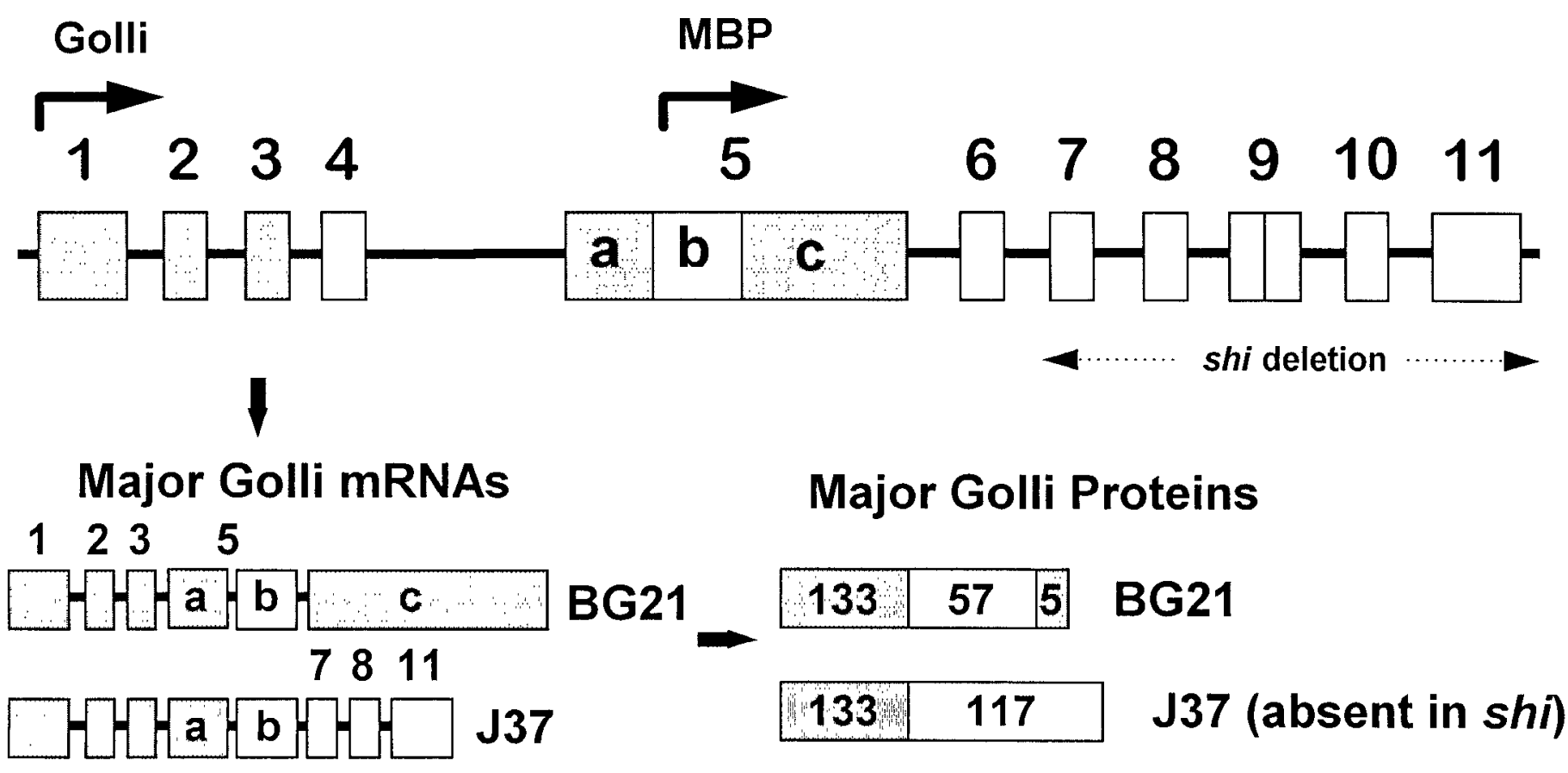

Major Golli Proteins

Figure 1. Schematic diagram of the golli-mbp transcription unit and the major golli products generated from this gene. The golli-mbp exon structure showing the two major (large forked arrows) transcription start sites is shown. Classical MBP transcripts are initiated within exon $5 \mathrm{~b}$ and golli transcripts within exon 1. Shaded boxes represent exons specific to golli mRNAs, and white boxes to MBP exons. A schermatic diagram of the two major golli mRNA species in postnatal mouse brain, and their corresponding protein products, is shown. The translation start site for golli protein products is found within exon 2. The golli proteins BG21 and J37 contain 133 amino acids of golli-specific 5 ' sequence followed by differing lengths of MBP sequence as shown. Note that the shi deletion would eliminate the $\mathfrak{J} 37$ transcript because of the deletion of exons 7, 8, and 11 in this mutant.

in situ hybridization. We have found that golli-mbp gene is expressed in neurons as well as oligodendrocytes, and that the BG21 golli protein product is the predominant isoform in postnatal mouse brain. In addition, the subcellular localization of the protein differed dramatically between neuronal populations and a shift in the subcellular location of golli protein during development was evident within specific populations of neurons.

\section{MATERIALS AND METHODS}

Probes

The cDNA insert G19, which encompassed golli-mbp exons 2 and 3, was subcloned into $\mathrm{pBS}^{+}$(Stratagene, La Jolla, CA) and linearized with $P v u \mathrm{II}$ or $B a m \mathrm{HI}$ for the production of antisense (T7 polymerase) or sense (T3 polymerase) riboprobe, respectively.

\section{Antibody production}

Recombinant protein. A cDNA encoding golli amino acids 1-133 was subcloned into pQE60 (Qiagen, Chatsworth, CA) and transformed into the Escherichia coli M15[pREP4]. In this vector the recombinant peptide produced contains six histidines at the $\mathrm{C}$ terminus to aid in isolation by chromatography on a $\mathrm{Ni}$ column. Recombinant peptide was induced, isolated and purified on a column of nickel nitrilo-triacetic acid resin (Hoffmann-LaRoche, Basel, Switzerland) according to the supplier's directions (Qiagen, Hilden, Germany). Histidine-labeled recombinant BG21 was produced in pQE70 (Qiagen), J37 in pET22 (Novagen, Madison, WI).

Antibody production. Recombinant protein was resuspended at 2.0 $\mathrm{mg} / \mathrm{ml}$ in phosphate buffer $\left(140 \mathrm{mM} \mathrm{NaCl} / 8 \mathrm{mM} \mathrm{Na}_{2} \mathrm{HPO}_{4} / 1.5 \mathrm{~mm}\right.$ $\mathrm{KH}_{2} \mathrm{PO}_{4} / 2.5 \mathrm{~mm} \mathrm{KCl}, \mathrm{pH} 7.0$ ). The antigen was mixed with an equal volume of Freund's complete adjuvant for the first injection and incomplete adjuvant for all subsequent booster injections. Rabbits were injected subcutaneously with a total of $1.0 \mathrm{ml}$ of antigen. Three weeks after the first injection, booster injections were administered every 2 weeks.

Affinity purification. Fifty milliliters of blood were collected from each rabbit and allowed to clot at room temperature for $30 \mathrm{~min}$, and the serum was separated by centrifugation using an Auto Isofilter Serum Filter
Isolator (Becton Dickinson, San Jose, CA). The serum was passed over a CM Affi-Gel Blue Gel (Bio-Rad, Richmond, CA) as directed by the manufacturer. The recovered antibody was applied to an affinity column containing recombinant golli peptide (1-133) coupled to Affi-Gel 10 (Bio-Rad). Nonspecific proteins were removed by washing the column extensively with phosphate buffer followed by $1 \mathrm{M} \mathrm{NaCl}$. Bound antibody was eluted with $0.1 \mathrm{M}$ glycine, $\mathrm{pH} 2.8$. Fractions containing the immunopurified antibody were pooled, stabilized by adding albumin to a final concentration of $0.5 \mathrm{mg} / \mathrm{ml}$, and then slowly neutralized by spin dialysis first with $0.3 \mathrm{M} \mathrm{NaOAc}, \mathrm{pH} 4.5$, followed by phosphate buffer.

Transfection of golli cDNA. Full-length J37 or BG21 cDNA were subcloned into the retroviral expression vector pBabe-puro (Morgenstern and Lund, 1990). Exponentially growing populations of the oligodendrocyteprecursor cell line, N19 (Verity et al., 1993) were transfected with either J37 or BG21-containing plasmid using a calcium phosphate method to obtain stably transformed cells (Chen and Okayama, 1988). Puromycin resistant colonies were selected by the addition of $3.0 \mu \mathrm{g} / \mathrm{ml}$ puromycin (Calbiochem, La Jolla, CA) to the medium.

\section{Western blots}

Western blots were prepared essentially as described previously (Kronquist et al., 1987). Briefly, brain and cell samples were either homoge nized in $10 \%$ SDS and boiled for $5 \mathrm{~min}$ or homogenized in loading buffer containing $8 \mathrm{~m}$ urea, $10 \mathrm{~mm}$ DTT, $4 \%$ SDS, $125 \mathrm{~mm}$ Tris $\mathrm{HCl}$, $\mathrm{pH}$ 6.8. No differences were observed in the Western blots obtained wheller or not the samples were subjected to boiling. Aliquots of $100 \mu \mathrm{g}$ of protein or 0.1 $\mu \mathrm{g}$ purified BG21 were separated on SDS polyacrylamide gels (Laemmli, 1970). The proteins were transferred to nitrocellulose by the method of Towbin et al. (1979). The total amount of protein loaded per lane was 100 $\mu \mathrm{g}$. Antigen-antibody complexes were detected by chemiluminescence (ECL, Amersham, Arlington Heights, IL).

\section{Synthesis of probes}

${ }^{33} \mathrm{P}$-labeled riboprobes were prepared by in vitro transcription using ${ }^{33}$ P-labeled UTP (DuPont NEN, Boston, MA) essentially as described by the manufacturer (Promega, Madison, WI). Riboprobes were generated at high specific activity by reducing the reaction volume to $10 \mu \mathrm{l}$ and 


\section{A \\ B}

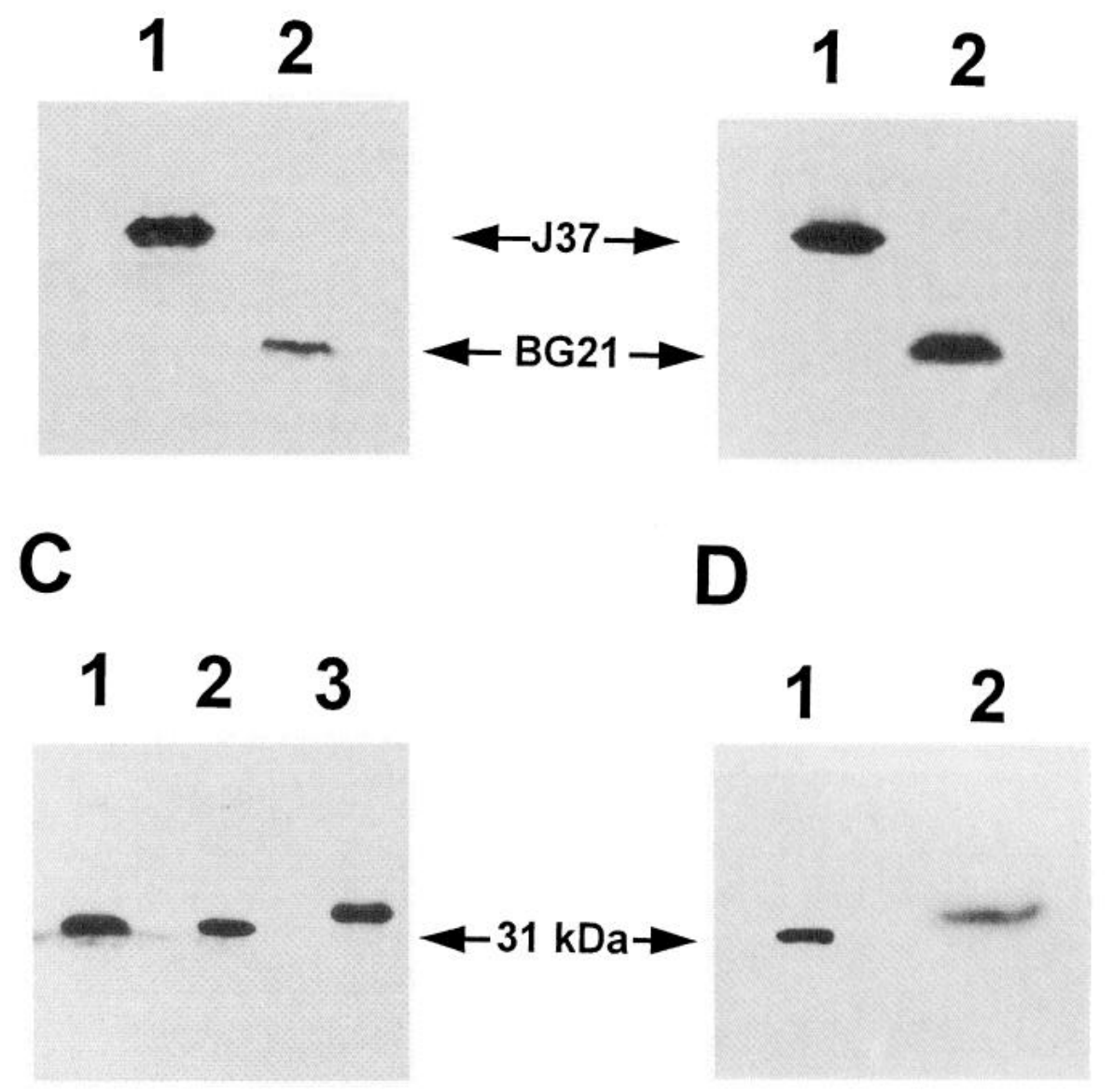

Figure 2. Antibody against a golli-specific peptide recognizes golli protein in normal and shi brain. $A$, Total cellular extracts from the oligodendrocyte cell line N19, stably transfected with either J37 (lane 1) or BG21 (lane 2) cDNA, were reacted with golli-specific antisera. The specific bands recognized in each cell line were identical in size to in vitro translation products of J37 and BG21 cRNA, 35 and $31 \mathrm{kDa}$, respectively (Campagnoni et al., 1993). B, An identical Western blot as $A$ was reacted with anti-bovine MBP antibody. Both $\mathrm{J} 37$ (lane 1) and BG21 (lane 2) were identified with this antibody. $C$, Protein extracts from $14 \mathrm{~d}$ (lane 1) and $28 \mathrm{~d}$ (lane 2) mouse brain were reacted with golli-specific antisera. A single $31 \mathrm{kDa}$ band was identified at both ages that corresponds to the observed size of BG21. Full-length recombinant BG21 peptide (lane 3) migrated slightly slower than these products because of the 6 histidine linker used for peptide purification. $D, \mathrm{BG} 21$ was also identified in Western blots from $16 \mathrm{~d}$ shi brain reacted with antigolli antibody (lane 1). Full-length recombinant BG21 peptide was run as a marker (lane 2). Note: samples prepared for blots $A, B$, and $D$ were boiled, and samples shown in $C$ were not boiled. No differences were observed whether or not the samples were boiled.

including only ${ }^{33} \mathrm{P}$-labeled UTP in the reaction mixture. We found that probes of high specific activity $\left(\sim 3 \times 10^{6} \mathrm{cpm} / \mathrm{ng}\right.$ probe $)$ were essential in identifying golli mRNA in in situ hybridization experiments because of the low amount of golli mRNA within neurons.

\section{Tissue preparation}

Mice (Balb/cByJ) were anesthetized with halothane (Halocarbon Laboratories, North Augusta, SC) and perfused intracardially with $0.1 \mathrm{~m}$ PBS, $\mathrm{pH} 7.2$, followed by $2 \%$ paraformaldehyde in PBS. Tissue was then post-fixed in $2 \%$ paraformaldehyde for $2 \mathrm{~d}$ at $4{ }^{\circ} \mathrm{C}$ and then equilibrated in $20 \%$ phosphate-buffered sucrose, $\mathrm{pH} 7.2$, for $16 \mathrm{hr}$, mounted in OCT embedding compound, and stored at $-70^{\circ} \mathrm{C}$ until use. For immunocytochemistry and in situ hybridization, frozen cryostat sections $(20 \mu \mathrm{m})$ were collected onto Superfrost Plus microscope slides (Fisher, Pittsburgh, PA) and stored dry at $-70^{\circ} \mathrm{C}$ until use.

\section{In situ hybridization histochemistry}

Before hybridization, sections were permeabilized in $0.2 \mathrm{M} \mathrm{HCl}$ for 10 min and then briefly digested with Proteinase $\mathrm{K}(0.5 \mu \mathrm{g} / \mathrm{ml})$ for $15 \mathrm{~min}$ at room temperature. After a $5 \mathrm{~min}$ post-fixation in $3.7 \%$ formaldehyde in PBS, slides were acetylated for 10 min with $0.25 \%$ acetic anhydride in 0.1 $\mathrm{M}$ triethanolamine, $\mathrm{pH}$ 8. Prehybridization was for $2 \mathrm{hr}$ at $60^{\circ} \mathrm{C}$ in a solution containing $50 \%$ formamide, $300 \mathrm{~mm} \mathrm{NaCl}, 4 \mathrm{~mm}$ EDTA, $80 \mathrm{~mm}$ Tris- $\mathrm{HCl}, \mathrm{pH} 8.0,0.1 \%$ Ficoll, $0.1 \%$ polyvinylpyrrolidone, $0.1 \%$ bovine serum albumin, $0.4 \%$ SDS, $250 \mu \mathrm{gm} / \mathrm{ml}$ tRNA, $25 \mu \mathrm{gm} / \mathrm{ml}$ poly A, and 25 $\mu \mathrm{gm} / \mathrm{ml}$ poly C. Sections were then hybridized overnight at $60^{\circ} \mathrm{C}$ in prehybridization solution containing $0.1 \mathrm{ng} / \mu \mathrm{l}^{33} \mathrm{P}$-labeled sense or antisense cRNA probe. After hybridization, sections were washed in $2 \times$ SSC $(1 \times \mathrm{SSC}=150 \mathrm{~mm} \mathrm{NaCl}, 15 \mathrm{~mm}$ citrate, $\mathrm{pH} \mathrm{7.0})$ for $1 \mathrm{hr}$ at room temperature and then digested for $30 \mathrm{~min}$ at $37^{\circ} \mathrm{C}$ in a solution containing $500 \mathrm{~mm} \mathrm{NaCl}, 1 \mathrm{~mm}$ EDTA, $10 \mathrm{~mm}$ Tris- $\mathrm{HCl}, \mathrm{pH} 7.5$, and $20 \mu \mathrm{gm} / \mathrm{ml}$ RNase A. Finally, sections were washed in RNase buffer without RNase $\left(30 \mathrm{~min}, 37^{\circ} \mathrm{C}\right), 2 \times \operatorname{SSC}\left(15 \mathrm{~min}, 37^{\circ} \mathrm{C}\right), 0.1 \times \mathrm{SSC}$ (twice for $15 \mathrm{~min}, 60^{\circ} \mathrm{C}$ ) and $1 \times \operatorname{SSC}\left(15 \mathrm{~min}, 25^{\circ} \mathrm{C}\right)$. For autoradiography, sections were exposed to $\beta$-max-hypersensitive film (Amersham, Arlington Heights, IL) for 48 $\mathrm{hr}$ and then NTB2 liquid emulsion for 4 weeks. Sections hybridized with ${ }^{33} \mathrm{P}$-labeled sense riboprobe were not labeled above background levels (data not shown).

\section{Immunocytochemistry}

Recombinant peptide corresponding to 133 amino acids of specific golli protein sequence was used to generate polyclonal antisera (Campagnoni et al., 1995). Anti-golli antisera was affinity purified against the peptide to ensure specific recognition of the target protein. Incubation of anti-golli antisera overnight in the presence of recombinant golli peptide (50 $\mu \mathrm{gm} / \mathrm{ml}$ ) completely abolished immunocytochemical staining (data not shown).

Frozen sections were dried at $37^{\circ} \mathrm{C}$ for $10 \mathrm{~min}$ and rinsed in PBS before immunocytochemistry. To quench for endogenous peroxidase activity, sections were incubated in a solution containing $0.3 \%$ hydrogen peroxide, $10 \%$ methanol in PBS for $10 \mathrm{~min}$. Sections were then incubated overnight at room temperature in anti-golli antibody (1:10,000 dilution) in PBS containing $0.1 \%$ Triton $\mathrm{X}-100,0.1 \%$ casein, and $0.1 \%$ sodium azide. After a PBS rinse, sections were incubated in anti-rabbit biotinylated secondary antibody, Vectastain Elite $\mathrm{ABC}$ reagent and peroxidase substrate solution as described by the manufacturers (Vector Laboratories, Burlingame, CA). Stain intensity was enhanced by the addition of nickel ammonium sulfate to the peroxidase substrate solution to a final concentration of $0.6 \%$. Sections were then dehydrated through an ethanol series and mounted in Permount. The results represent at least three independent experiments using tissue from different animals.

\section{RESULTS}

The structure of the golli-mbp transcription unit, and its relationship to the MBP transcription unit, is outlined in Figure 1. Golli 


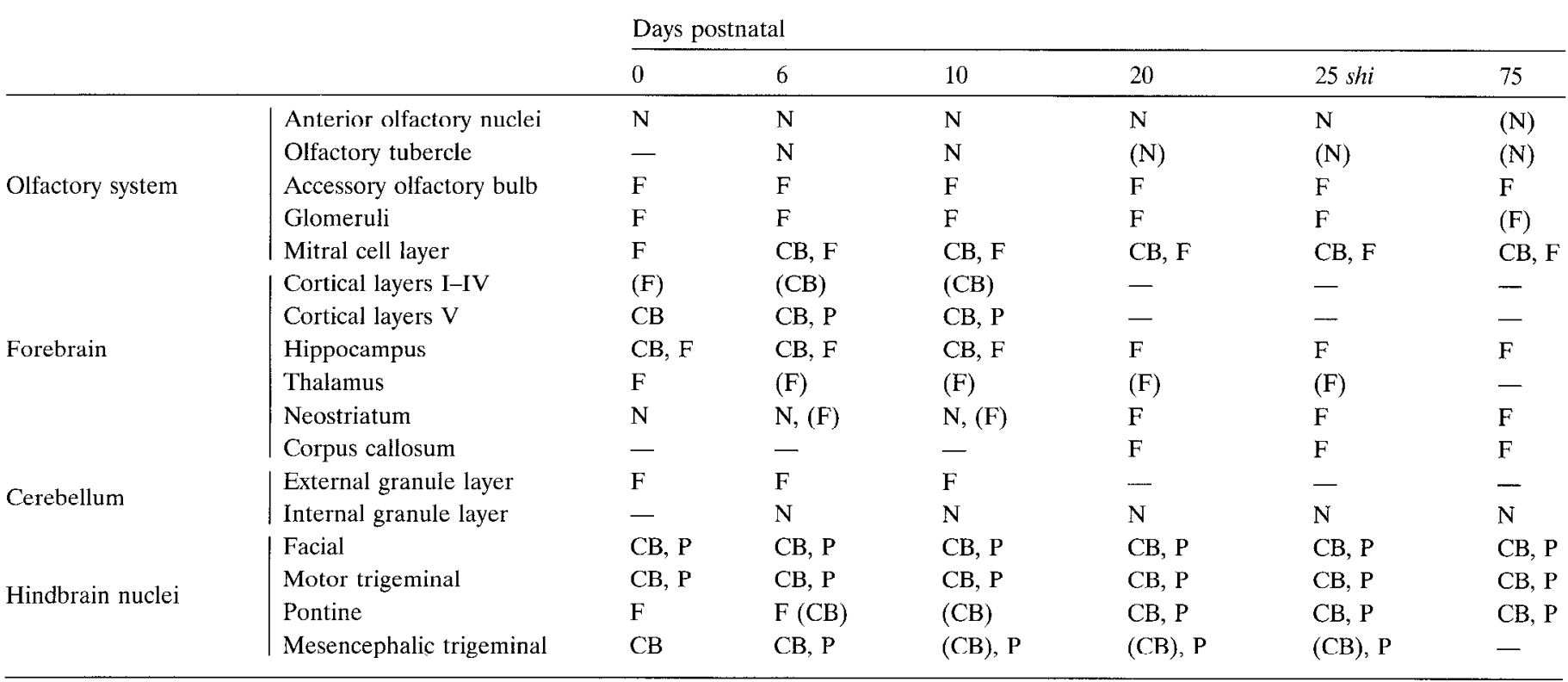

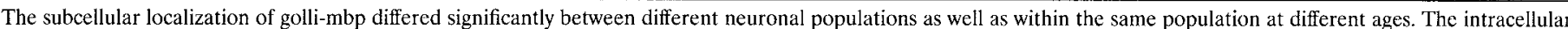

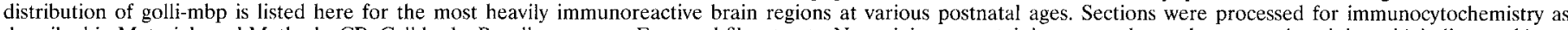

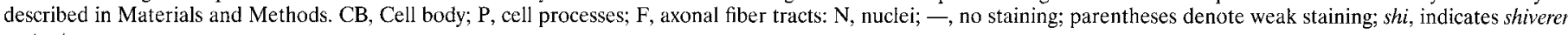
mutant mouse.

transcripts are produced from exon 1 and the MBP transcripts are produced primarily from exon 5b (Campagnoni et al., 1993; Pribyl et al., 1993). In the mouse brain, two major golli mRNAs of 5.1 and $2.6 \mathrm{~kb}$ have been identified (Fig. 1). These transcripts encode novel proteins (BG21 and J37, respectively) that contain 133 amino acids (shown in gray in Fig. 1) fused to MBP amino acid sequences (shown in white in Fig. 1). The shi mutant, which contains a deletion of golli-mbp exons 7-11 (MBP exons 3-7), would transcribe the $5.1 \mathrm{~kb}$ golli mRNA only.

To identify golli protein expression during postnatal brain development, polyclonal antisera were generated against the unique 133 amino acid golli peptide sequence. The antisera were affinity purified against the peptide and it was found to specifically recognize both BG21 and $\mathrm{J} 37$ in total cell lysates of a mouse oligodendrocyte cell line (N19; Verity et al., 1993) that was stably transfected with full-length $\mathrm{BG} 21$ or $\mathrm{J} 37$ mouse golli cDNAs (Fig. $2 A$ ). Proteins of 31 and $35 \mathrm{kDa}$ corresponding to BG21 and J37, respectively, were recognized by the antibody (Fig. $2 A$ ). An identical Western blot, probed with an anti-bovine MBP antibody, recognized the same two bands because of MBP epitopes within the C-terminal ends of the golli proteins (Fig. 2B). On Western blots from postnatal mouse brain, a single $31 \mathrm{kDa}$ band corresponding to BG21 was recognized in both 14 and $28 \mathrm{~d}$ brain (Fig. $2 C$, lanes 1,2 ). The protein band from the tissues migrated faster than the recombinant BG21 standard because the recombinant protein contains an additional eight amino acids at its $\mathrm{C}$ terminus that were used in isolation and purification. To confirm the identity of this immunoreactive species, we also prepared a Western blot on protein from mutant shi brain and found an identical $31 \mathrm{kDa}$ band corresponding to BG21 (Fig. 2D, lane 2). Interestingly, we did not find a band on Western blots from brain corresponding to $\mathbf{J} 37$ although the antibody was able to recognize the recombinant $\mathrm{J} 37$ protein (data not shown) as well as $\mathrm{J} 37$ expressed in transfected cells (Fig. $2 A$, lane 1 ). $\mathrm{J} 37$, therefore, appears to be a minor golli protein isoform in postnatal mouse brain. To exam- ine further the expression of golli mRNA and protein during postnatal brain development, we examined mouse brain from 0 to $75 \mathrm{~d}$ after birth by in situ hybridization and immunocytochemistry.

\section{Golli protein is present within neuronal processes}

Golli protein immunoreactivity was present within axonal fibers as early as postnatal day 0 . Specific fiber tracts such as the habenulopeduncular tract were easily identified by virtue of their intense staining with antibody to golli protein (Fig. $3 A$ ). Although fiber tracts in other brain regions were also labeled (see Table 1), many fiber tracts were not stained with anti-golli antibody (Fig. $3 B$ ). Immunoreactivity was also identified within the dendritic processes of specific neuronal populations. In some neurons, such as the mitral cells of the accessory olfactory bulb (AOB), golli protein was not detected in the cell soma but was evident within the long dendritic processes of these cells as they extend into the glomerular layer (Fig. 3C). In adjacent sections of AOB hybridized with antisense probe to golli mRNA, label corresponding to golli mRNA was confined to mitral cell bodies, suggesting that the protcin is transportcd into cell processes (Fig. $3 D$ ). In some neuronal populations golli protein was found in both cell bodies and cell processes. Within the olfactory bulb proper, for example, another population of mitral neurons were found to express golli protein in cell soma as well as in dendritic branches (arrows in Fig. $3 E$ ). Again, in adjacent sections processed for in situ hybridization, golli mRNA appeared to be confined to the cell soma of mitral cells (Fig. $3 F$ ).

\section{Golli protein is developmentally regulated in certain neurons}

Golli protein was found to decrease in specific neuronal populations during development. The large pyramidal neurons of layer $\mathrm{V}$ of neocortex, for example, were intensely stained during the first postnatal week (Fig. $4 A$ ). Stain was evident within the cell soma as well as within the long apical dendrites characteristic of these 

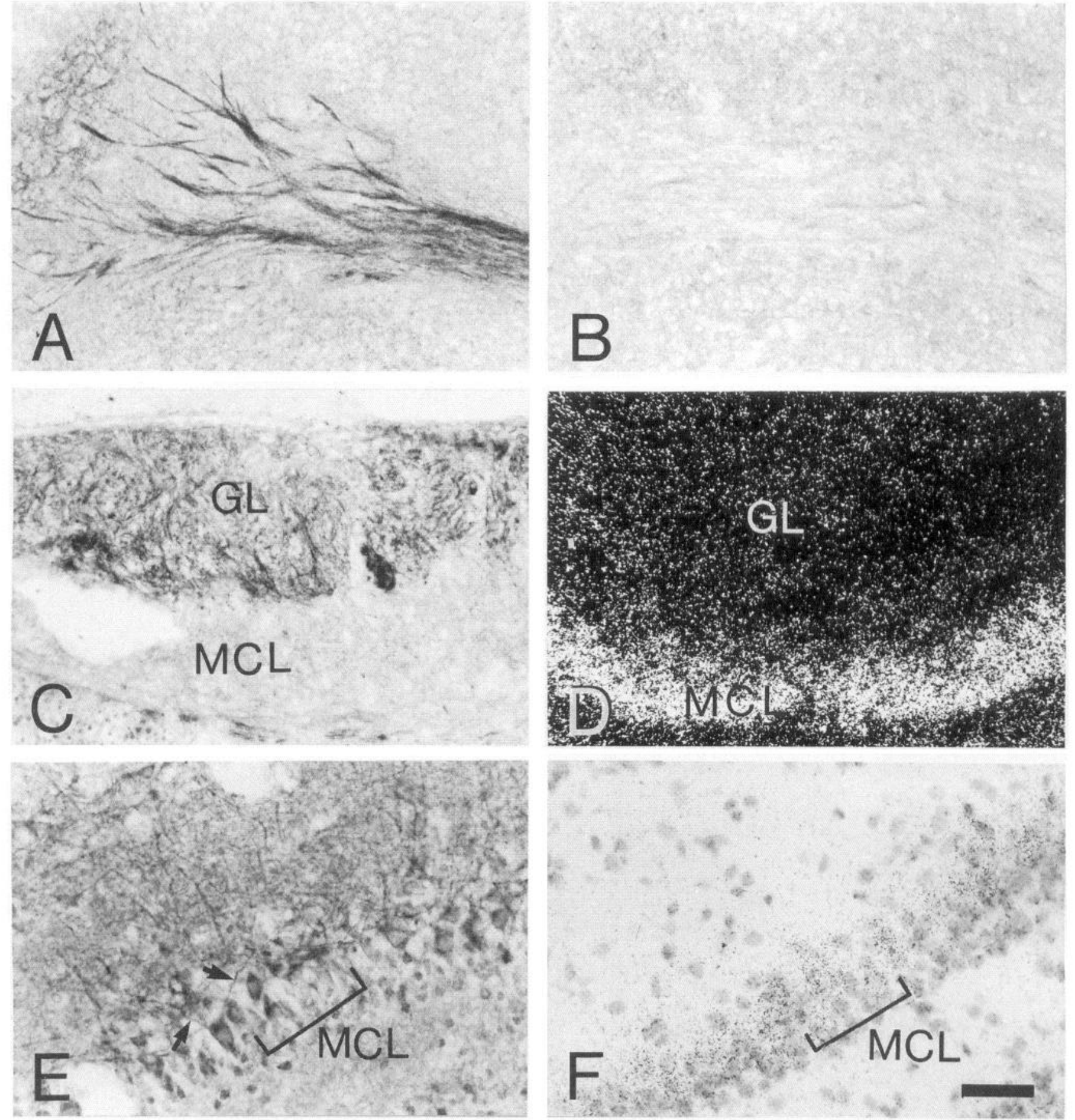

Figure 3. Golli protein is found within the processes of neurons in postnatal mouse brain. $A$, The habenulopeduncular tract was intensely stained with antibody to golli protein in P0 mouse brain. $B$, The mammalothalamic tract was unstained in the P0 animal and remained unstained throughout development. $C$, In the AOB at P6, golli protein immunoreactivity was evident in fibers within the glomerular layer. Neuronal layers, such as the mitral cell layer, were unstained. D. Adjacent sections from P6 mouse brain hybridized with ${ }^{33} \mathrm{P}$-labeled golli-specific antisense riboprobe revealed strong signal within cells of the mitral cell layer (dark-field micrograph). $E$, In the olfactory bulb proper, golli protein staining was evident within both the soma and the dendritic processes of mitral cells (P10 animal). Note that stained dendritic processes (arrows) could be found emerging from mitral cell soma. $F$, Adjacent sections hybridized with ${ }^{33} \mathrm{P}$-labeled antisense riboprobe confirm the presence of golli mRNA within the soma of these cells (bright-field micrograph). Scale bar: $A-D, 100 \mu \mathrm{m} ; E, F, 50 \mu \mathrm{m}$. $G L$, Glomerular layer; $M C L$, mitral cell layer.

cells. Stain intensity within these cells diminished with age so that by $\mathrm{P} 75$, little golli protein staining was apparent (Fig. $4 B$ ). Neurons of the mesencephalic trigeminal nucleus were also heavily stained in P6 animals (Fig. 4C). Golli protein immunoreactivity was found within the soma of these cells as well as within the long, sinuous fibers that coursed through this region (arrows in Fig. 4C).
By P75, these large midbrain neurons were only faintly stained with antibody to golli protein (Fig. 4D).

In certain brain regions, golli protein was found exclusively in the nucleus of specific neuronal populations. Neurons within the olfactory tubercle, for example, contained heavily stained nuclei but unstained cytoplasm and processes (Fig. 5A). A 

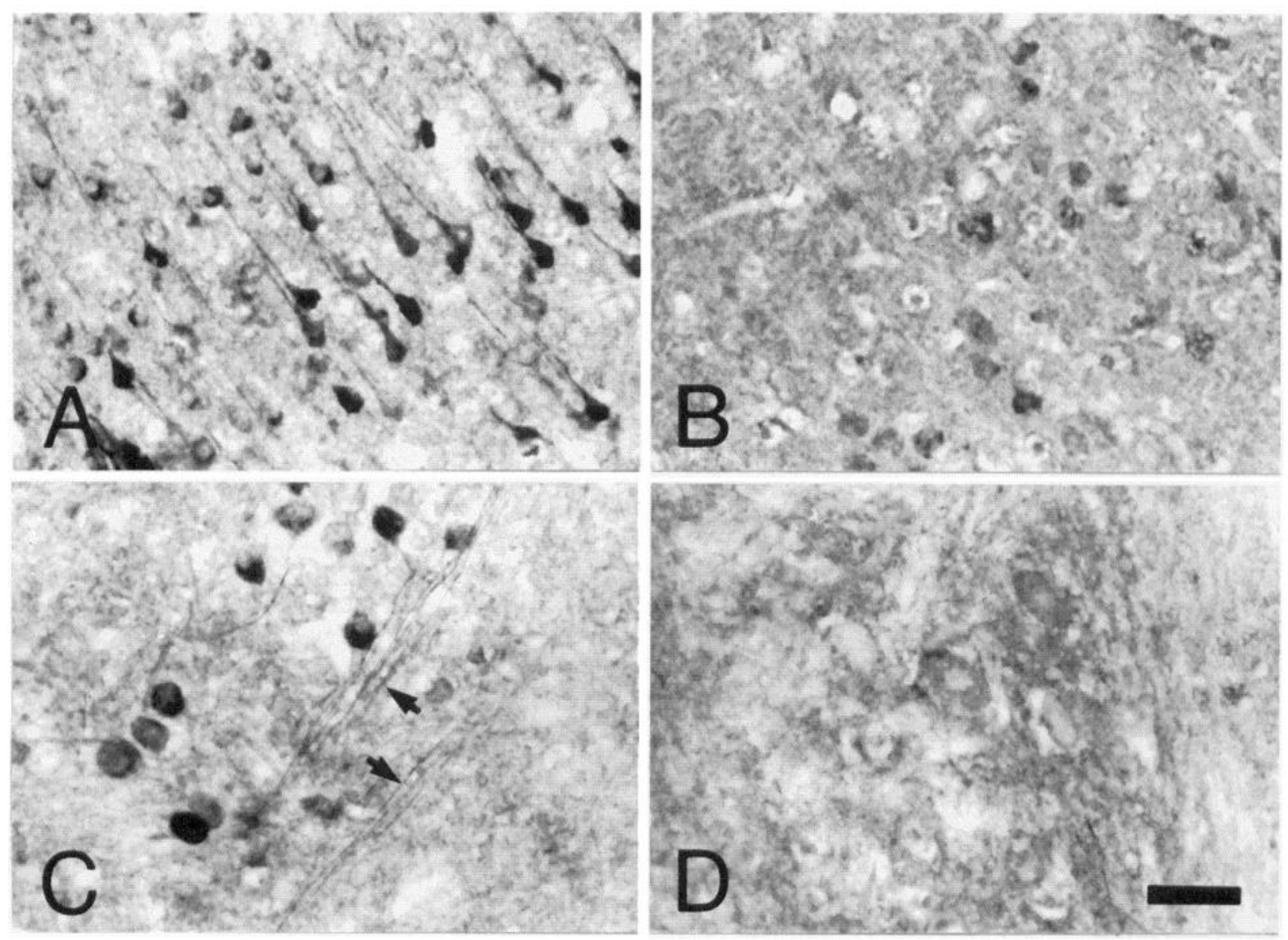

Figure 4. Golli protein immunoreactivity declines significantly within specific midbrain and cortical neurons during development. $A$, Intense staining with antibody to golli protein was evident within cortical neurons of layer V of P6 mouse brain. Immunoreactivity was evident within the cell bodies as well as within apical dendrites. B, By P75, staining within layer $\mathrm{V}$ was greatly reduced and only a few cells were found to contain faint staining within their cell soma. $C$, Neurons of the mesencephalic trigeminal nucleus were also intensely immunoreactive in $\mathrm{P} 6$ animals. In addition to strong staining within the soma of these cells, golli protein immunoreactivity was also evident within numerous thin axonal fibers (arrows) that emanated from this region. $D$, By P75, only faint staining was evident within the soma of these neurons. Scale bar: $A, B, 60 \mu \mathrm{m} ; C, D, 45 \mu \mathrm{m}$.

nuclear staining pattern within this and other cell populations was most apparent within the first postnatal week and seemed to decline as the brain matured. This was most clearly evident within neurons of the neostriatum. At P6 (Fig. 5B), immunoreactivity within these cells was confined exclusively to the nucleus with no evidence of labeling in the cytoplasm or processes of these cells. At P10, stain within the nucleus of neostriatal neurons persisted but staining within fibrous regions became apparent (Fig. 5C). By P20, staining within the nucleus of neostriatal neurons had disappeared (Fig. 5D). Mottled staining persisted within this region and fibrous staining was evident. However, we were unable to determine whether the stained fibers emanated from neostriatal neurons or from neurons residing outside the neostriatum. It is unclear, therefore, whether golli expression ceased within these cells or whether the subcellular distribution of the protein changed.

\section{The subcellular localization of golli protein is regulated during development}

In addition to the disappearance and attenuation of golli-mbp expression within neurons, the subcellular location of the protein was also found to change in some neurons as the brain matured. In P6 mouse brain, golli protein immunoreactivity was found within pyramidal cells of the hippocampus as well as within granule cells of the dentate gyrus (Fig. $6 A$ ). In addition, fibers emanating from the dentate gyrus and extending into the pyramidal cell layer were also stained (small arrows in Fig. 6A). At later developmental ages, the relative staining intensely increased within axonal fibers of this region but was greatly reduced within the neuronal cell populations. By P75, pyramidal and granule cell bodies were unstained with anti-golli antibody but fibers extending from the granule cell layer of dentate gyrus were intensely stained (Fig. 6B). These axons correspond to the mossy fibers of the dentate gyrus that innervate CA3 pyramidal neurons exclusively, as is indicated by golli protein immunoreactivity. In situ hybridization of adjacent sections of P75 mouse brain hybridized with antisense probe to golli mRNAs revealed strong expression of golli mRNA within granule cells of the dentate gyrus confirming that these cells synthesize the golli protein identified within mossy fibers (Fig. 6D). Golli protein was also present within the hippocampus of mutant shi mice (Fig. $6 \mathrm{C}$ ). The pattern of golli protein staining during development was indistinguishable in these animals from that observed in normal mice. In P25 shi brain, for example, mossy fibers were deeply stained with antibody to golli protein whereas neuronal cell bodies were unstained (Fig. $6 C)$. Because these animals contain a deletion of the classical MBP exons 3-7 (golli exons 7-11), the golli protein present within hippocampus can only correspond to the golli protein isoform, BG21. 

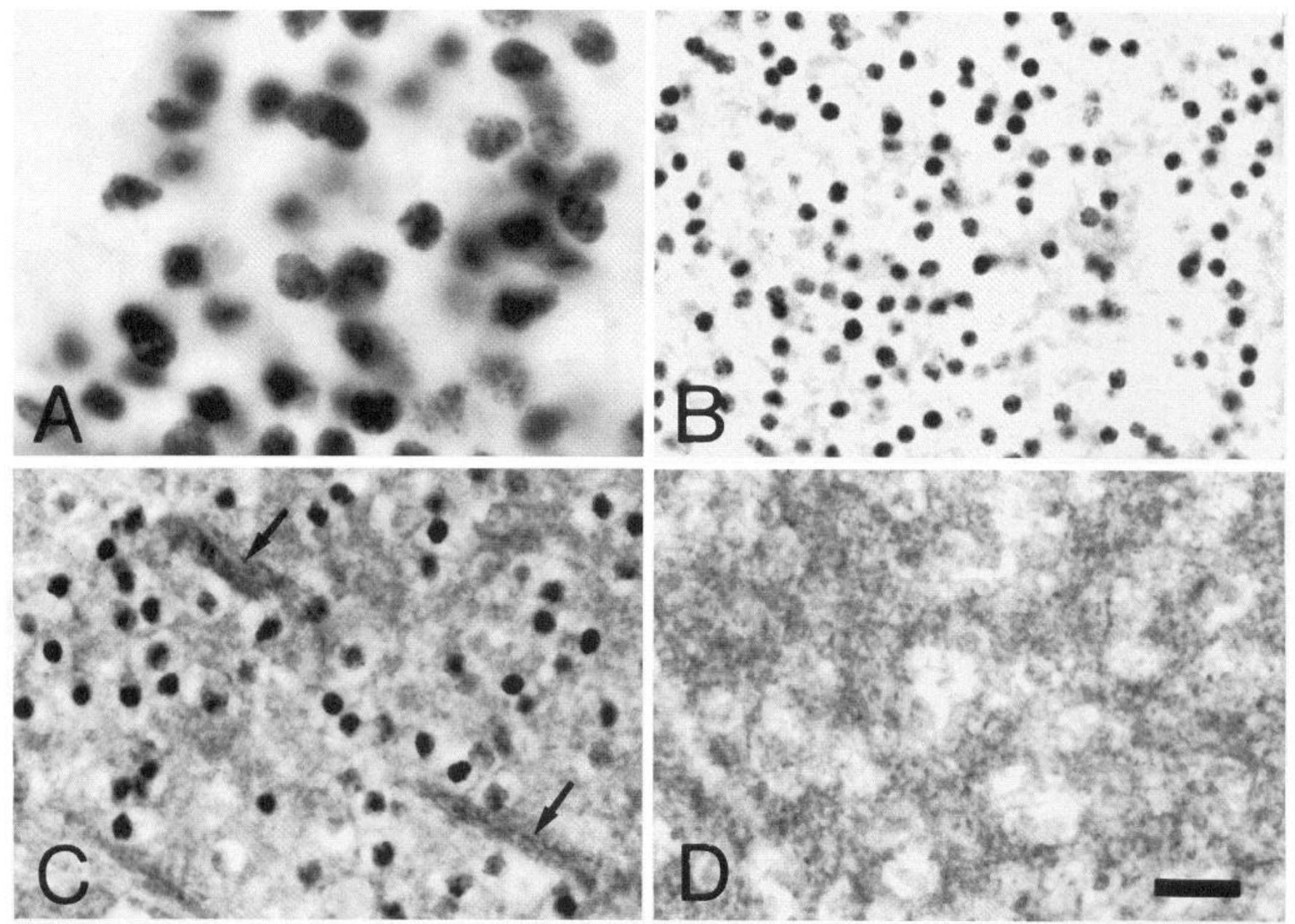

Figure 5. A nuclear localization of golli protein is evident within specific neuronal populations and disappears from neostriatal neurons as they mature. $A$, A strong nuclear localization of golli protein immunoreactivity was confined to the nucleus of neurons within the olfactory tubercle of P10 animals. $B$, Within P6 neostriatum, stain to golli protein was confined to the nuclei of neurons within this region. $C$, At P10, golli protein within the nucleus of neostriatal neurons persisted but appeared to be relatively less intense compared with younger ages. In addition, staining within axonal fibers (arrows) became apparent. $D$, By $\mathrm{P} 20$, staining within the nucleus of neostriatal neurons had disappeared. Scale bar: $A, 10 \mu \mathrm{m} ; B-D, 30 \mu \mathrm{m}$.

In the cerebellum, granule cells expressed golli protein before migration and continued to express the protein into adulthood. At P6, golli protein immunoreactivity was evident within both the external and internal granule cell layers, although staining within external granule cells was less prominent (Fig. $7 A$ ). Figure $7 B$ illustrates an in situ hybridization $\mathrm{x}$-ray autoradiogram pattern produced from an adjacent P6 section hybridized with antisense probe to golli mRNA. Note that heavy silver grain accumulation was evident within the external granule cell layer, confirming that these cells contain golli mRNA. At higher magnification, migrating granule cells stained with antibody to golli protein were identified within the molecular layer of cerebellum (arrowheads in Fig. $7 C$ ). Interestingly, the nuclei of these migrating cells stained intensely with anti-golli antibody as did the nuclei of those cells found within the internal granule cell layer, their final destination. Within the external granule cell layer, however, the staining pattern appeared to be more fibrous in nature and stained nuclei were not observed. The fibrous staining pattern observed in P6 brain was more apparent at P10 (Fig. 7D). Although it was difficult to determine whether the staining was cytoplasmic, it was found to extend into the molecular layer in a feathered, process-like pattern. Staining within the internal granule cells, in contrast, was strongly nuclear in localization. In adjacent sections processed for in situ hybridization and photographed in bright field, golli mRNA was evident in both the external and internal granule cell layers (Fig. $7 F$ ), consistent with the localization of golli protein in these cells. By P20, the adult pattern of staining was established and numerous granule cell neurons were prominently stained for golli protein (Fig. 7E).

A summary of the brain regions that express golli protein is shown in Table 1. A number of postnatal ages are included in the table to emphasize the influence of development on the shift in subcellular localization of golli protein. Note that the pattern of golli protein staining was indistinguishable in P20 normal and P25 shi throughout the brain. An indistinguishable staining pattern was also evident in comparisons of younger (P6) shi and normal animals and in comparisons of in situ hybridization data (not shown), confirming that the major golli protein in postnatal rodent brain is BG21.

\section{DISCUSSION}

In this report, we describe the expression of golli protein in neuronal cells, the first report of MBP gene expression in nonglial cells in the murine CNS. Concordance between the cellular distribution of golli protein immunoreactivity and golli mRNA in situ hybridization labeling in specific neuronal populations is good 

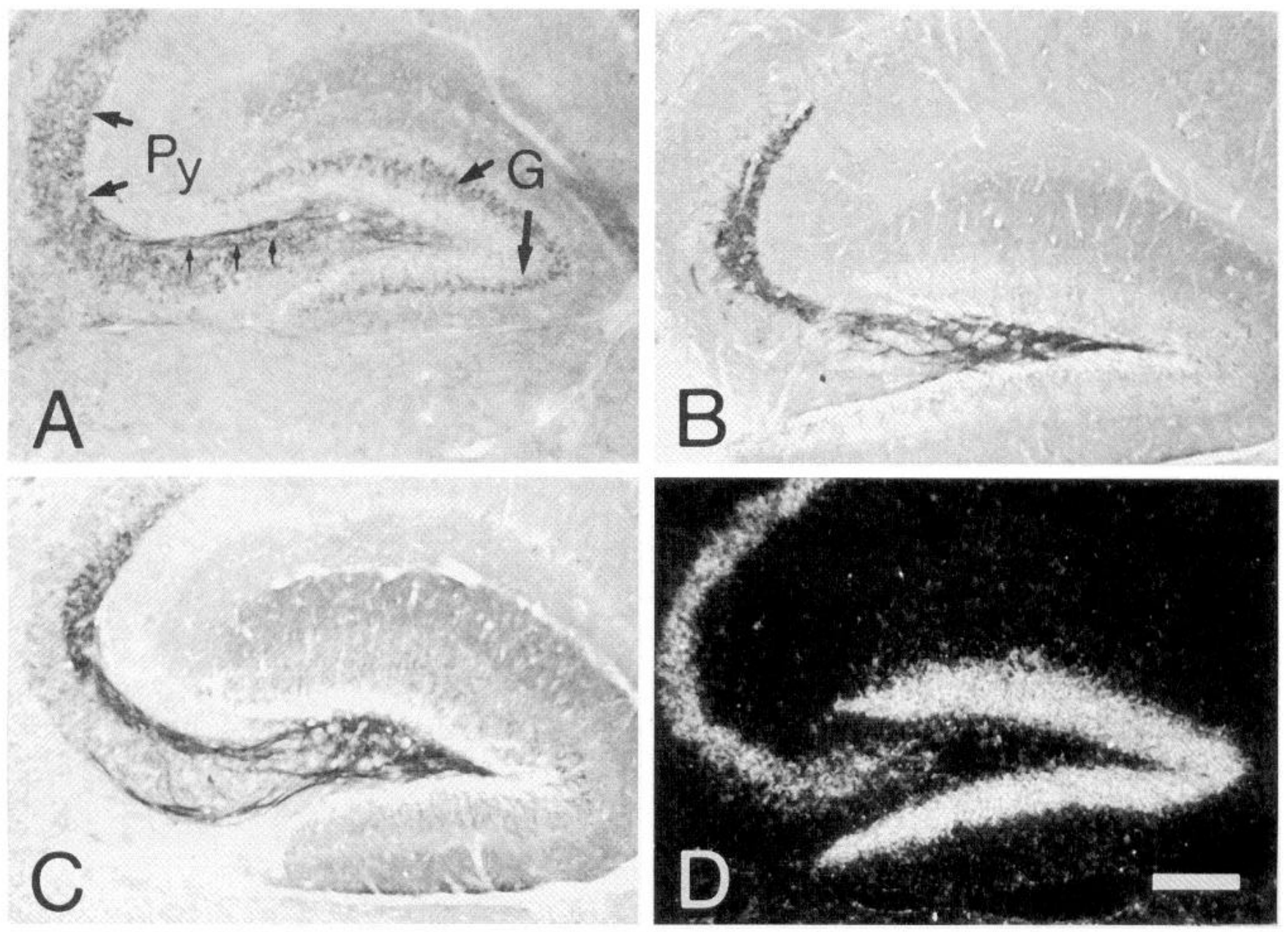

Figure 6. Golli protein shifts from cell bodies to the mossy fibers of dentate granule cells during development. A, In P6 mouse brain, antibody to golli protein stained both pyramidal cells of the hippocampus and granule cells of the dentate gyrus. Note that staining within mossy fiber granule cell axons was also evident at this age (small arrows). B, By P75, mossy fibers were intensely stained for golli protein. $C$, An indistinguishable staining pattern within the mossy fibers of mutant shi animals was apparent. Note that the golli protein identified within these axons must correspond to the BG21 form of the peptide because the deletion of golli-mbp exons 7-11 would exclude the J37 transcript in these mutants. $D$, An in situ hybridization dark-field micrograph of an adjacent section to $B$ hybridized with antisense golli riboprobe. Note the high levels of labeling within the granule cell layer of the dentate gyrus. Scale bar, $180 \mu \mathrm{m}$. Py, Pyramidal cell layer of hippocampus; $G$, granule cell layer of dentate gyrus.

evidence for the synthesis of golli protein in these cells. The predominant location of golli immunoreactivity was within neuronal processes, but in a few groups of neurons, staining was localized within nuclei. In addition, the subcellular location of golli protein differed dramatically among neuronal groups. These results indicate that golli proteins and MBPs perform different functions in neural cells in spite of the MBP sequences they share in common.

The major isoform of golli protein in postnatal mouse brain appears to be BG21, generated from the $5.1 \mathrm{~kb}$ mRNA that terminates in exon $5 \mathrm{C}$ (intron 1 of the classical MBP nomenclature). Of the two major golli mRNA species (5.1 and $2.6 \mathrm{~kb}$ ) identified on Northern blots from postnatal mouse brain, the $5.1 \mathrm{~kb}$ species is the most prominent (Campagnoni et al., 1993). A much less abundant species called TP8 $(2.2 \mathrm{~kb})$ has also been identified and sequenced. The presence of other golli-like transcripts in postnatal brain has been suggested from PCR studies (Zelenika et al., 1993); however, none of these were characterized or sequenced. Furthermore, the authors did not determine whether these putative transcripts were generated from the golli-mbp promoter so their identity is not certain. Our own unpublished studies on human brain suggest that other golli-mbp splice products account for only a minor proportion of golli mRNA (K. Kampf, C. Campagnoni, and T. Pribyl, unpublished data).

In this study, we found that the pattern of golli protein immunoreactivity in brains of shi mice was indistinguishable from that observed in normal animals. Because shi mutants contain a deletion in golli-mbp exons 7-11, the BG21 form of golli protein would be the only characterized mRNA generated as a full-length transcript. The lack of a clear immunoreactivity in normal animals that would correspond to the golli proteins J37 or TP8 (generated from the less abundant mRNAs identified in postnatal brain) may result from the relative lower abundance of these species.

We have previously identified golli mRNA expression in oligodendrocytes and their precursors in mouse brain white matter regions and in primary cultures (Campagnoni et al., 1993). Using more stringent permeabilization conditions than those used in this study (e.g., sodium borohydride treament), we have been able to detect golli protein immunoreactivity within oligodendrocyte cell bodies and processes of fetal human spinal cord (T. Pribyl, C. Campagnoni, K. Kampf, J. Ellison, C. Landry, T. Kashima, J. McMahon, and A. Campagnoni, unpublished observations). Furthermore, we also can detect golli immunoreactivity in mouse 

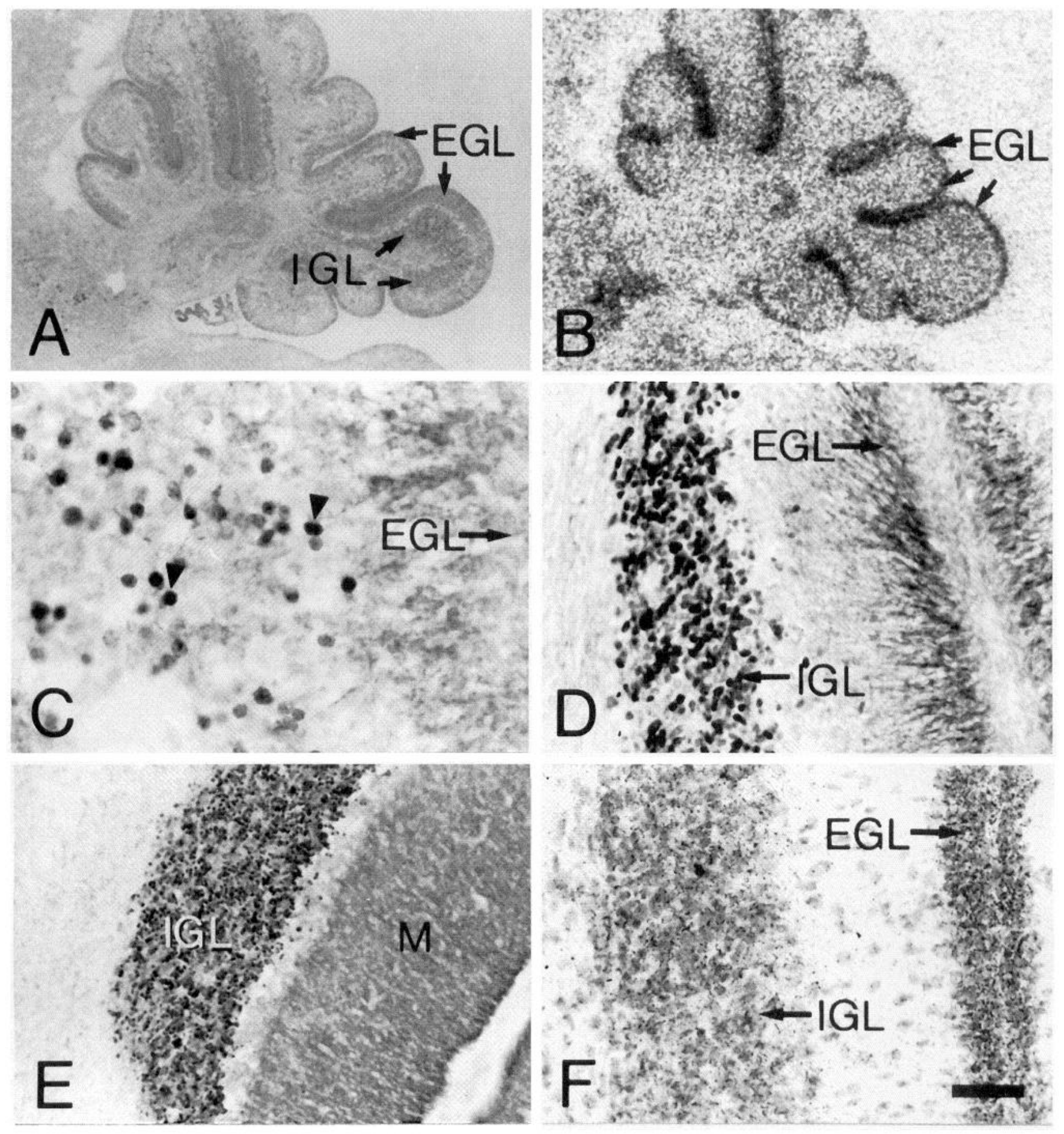

Figure 7. Golli expression in cerebellar granule cells begins before migration and persists into maturation. A, Golli protein immunoreactivity in the internal and external granule cell layer of the cerebellum at P6. B, An adjacent sagittal section hybridized with golli-specific antisense riboprobe and visualized using $\mathrm{x}$-ray film. $C$, At higher magnification, granule cells migrating through the molecular layer were found to contain golli protein within their nuclei (arrowheads). A feathered staining pattern extending from the external granule layer was consistently seen. Note that the nuclei of external granule cells were unstained. $D$, By P10, the nuclei of postmigratory granule cells in the internal layer were deeply stained. In addition, a feathered, process-like staining pattern was evident within the external granule cell layer. $E$, By $\mathrm{P} 20$, golli protein staining in cerebellum was confined to internal granule cell neurons, although lower levels of stain were also evident within the molecular layer. $F$, An adjacent section to the P10 brain in $D$ was hybridized with riboprobe to golli mRNA. In a bright-field micrograph, both the external and the internal granule cell layers are found to express golli mRNA. Scale bar: $A, B, 400 \mu \mathrm{m} ; C, 30 \mu \mathrm{m} ; D, F, 50 \mu \mathrm{m} ; E, 100 \mu \mathrm{m}$. EGL, External granule cell layer; $I G L$, internal granule cell layer; $M$, molecular layer.

brain primary oligodendrocyte cultures (J. Ellison, S. AmurUmarjee, and A. Campagnoni, unpublished data). Thus, golli proteins are expressed by both oligodendrocytes and neurons; however, under the permeability conditions used in this study, the cells most reactive with the antiserum appear to be neurons.
In most groups of neurons, golli-mbp gene expression ceased during postnatal development as, for example, in the pyramidal cells of layer $\mathrm{V}$ of neocortex. This decrease in golli protein expression within cell processes roughly coincided with the onset of myelination and may parallel a specific period of 
neuronal maturation. In this regard, it is interesting that in three groups of neurons without myelinated axons there was not a decrease in golli-mbp gene expression, although a shift in the subcellular location of golli proteins occurred in two groups of these neurons during development. These three groups were cerebellar granule cells, the granule cells of the dentate gyrus, and the cells of the olfactory epithelium. Whether a developmental event like myelination influences the regulation or subcellular location of golli protein remains to be determined. Clearly, however, the mechanisms that regulate the expression and subcellular localization of the protein appear to be unique to individual neuronal populations.

The selective localization of golli protein within the nuclei of specific neuronal populations implies that golli protein is actively transported into the nucleus. Consistent with this notion is the presence of basic amino acid clusters within both the golli portion and MBP portion of the molecule that are similar to nuclear localization signals (Kalderon et al., 1984; Silver and Goodson, 1989). Certain MBP isoforms have been found to be targeted to the nucleus of cells transfected in culture (Allinquant et al., 1991). In our study, the pattern of immunocytochemical staining for golli protein was similar to that of other nuclear proteins (Wetmore et al., 1991; Larsen and Mikkelsen, 1995). Unlike structural proteins of the nucleus, however, golli protein was only transiently present within the nucleus of some golli-positive neurons and excluded from the nucleus of others. This kind of specificity is reminiscent of transcription factors that are induced within specific neurons only under certain conditions (Morgan et al., 1987; Dragunow and Robertson, 1988). Similarly, proteins such as basic fibroblast growth factor and int-2, which are present primarily within the cytoplasm of cells, have also been identified within cell nuclei under certain conditions (Acland et al., 1990; Dickson and Acland, 1990; Dono and Zeller, 1994; Riese et al., 1995). It has also been observed that some proteins involved in gene activation are regulated during early vertebrate development by a redistribution of protein from the cytoplasm to the nucleus (Dreyer, 1987; Messmer and Dreyer, 1993). By analogy, the golli protein may serve a role in transcription, and its cellular redistribution in neostriatal neurons and cerebellar granule cells during development may indicate that its nuclear targeting is itself a regulated phenomenon.

An alternate explanation for the variation in subcellular location of golli protein in neurons is that different golli protein isoforms are localized to different cellular domains. This possibility is unlikely because the pattern of golli protein staining in the brains of mutant shi mice was indistinguishable to normal animals. Because shi mutants contain a deletion in golli-mbp exons $7-11$, the only golli product expressed by the mutant is BG21.

The expression of the golli promoter in specific groups of neurons underscores the complex regulatory mechanisms under which the golli-mbp transcription unit is controlled. The results from this report further indicate that the two major promoters of the golli-mbp gene are under independent developmental regulation. In the CNS, the MBP promoter functions exclusively in oligodendrocytes and becomes transcriptionally active at a later stage of oligodendrocyte differentiation. The golli promoter, in contrast, is less restricted in cell type expression but is under more complex regulation because it is transiently expressed in certain cells such as neurons of the trigeminal nucleus. Interestingly, in some respects expression of the golli-mbp gene is similar to the dystrophin gene, which contains promoters that are expressed in specific cortical and cerebellar neuronal populations (Ahn and Kunkel, 1993). In addition to these neuronal promoters, the dystrophin gene also contains a downstream promoter that generates a truncated form of dystrophin that functions exclusively in Schwann cells of the PNS (Byers et al., 1993), a direct parallel to the MBP promoter within the golli-mbp gene complex. Both genes, therefore, produce unique proteins by placing successively downstream exons under independent promoter regulation. This mechanism may be a general mechanism for the generation of diversity in the nervous system and one in which functionally different proteins that contain shared sequences are targeted to different cells of the nervous system.

\section{REFERENCES}

Acland P, Dixon M, Peters G, Dickson C (1990) Subcellular fate of the int-2 oncoprotein is determined by choice of initiation codon. Nature 343:662-665.

Ahn AH, Kunkel LM (1993) The structural and functional diversity of dystrophin. Nature Genet 3:283-291.

Allinquant B, Staugaitis SM, D'Urso D, Colman DR (1991) The ectopic expression of myelin basic protein isoforms in shiverer oligodendrocytes: implications for myelinogenesis. J Cell Biol 113: 393-403.

Aruga J, Okano H, Mikoshiba K (1991) Identification of the new isoforms of mouse myelin basic protein: the existence of exon 5a. J Neurochem 56:1222-1226.

Byers TJ, Lidov HG, Kunkel LM (1993) An alternative dystrophin transcript specific to peripheral nerve. Nature Genet 4:77-81.

Campagnoni AT, Macklin WB (1988) Cellular and molecular aspects of myelin protein gene expression. Mol Neurobiol 2:41-89.

Campagnoni AT, Pribyl TM, Campagnoni CW, Kampf K, Amur-Umarjee S, Landry CF, Handley VW, Newman SL, Garbay B, Kitamura K (1993) Structure and developmental regulation of Golli-mbp, a 105kilobase gene that encompasses the myelin basic protein gene and is expressed in cells in the oligodendrocyte lineage in the brain. $J$ Biol Chem 268:4930-4938.

Campagnoni CW, Kampf K, Pribyl TM, Foster L, Campagnoni AT (1995) Expression of golli proteins in transfected oligodendroglial cell lines. J Neurochem 64:\$64.

Chen CA, Okayama H (1988) Calcium phosphate-mediated gene transfer: a highly efficient transfection system for stably transforming cells with plasmid DNA. Biotechniques 6:632-638.

de Ferra F, Engh H, Hudson L, Kamholz J, Puckett C, Molineaux S, Lazzarini RA (1985) Alternate splicing accounts for the four forms of myelin basic protein. Cell 43:721-727.

Dickson C, Acland P (1990) Int-2: a member of the fihrohlast growth factor family has different subcellular fates depending on the choice of initiation codon. Enzyme 44:225-234.

Dono R, Zeller R (1991) Cell-type-specific nuclear translocation of fibroblast growth factor-2 isoforms during chicken kidney and limb morphogenesis. Dev Biol 163:316-330.

Dragunow M, Robertson HA (1988) Localization and induction of c-fos protein-like immunoreactive material in the nuclei of adult mammalian neurons. Brain Res 440:252-260.

Dreyer C (1987) Differential accumulation of oocyte nuclear proteins by embryonic nuclei of Xenopus. Development 101:829-846.

Kalderon D, Roberts BL, Richardson WD, Smith AE (1984) A short amino acid sequence able to specify nuclear location. Cell 39:499-509.

Kamholz J, Toffenetti J, Lazzarini RA (1988) Organization and expression of the human myelin basic protein gene. I Neurosci Res 21:62-70.

Kimura M, Sato M, Akatsuka A, Nozawa-Kimura S, Takahashi R, Yokoyama M, Nomura T, Katsuki M (1989) Restoration of myelin formation by a single type of myelin basic protein in transgenic shiverer mice. Proc Natl Acad Sci USA 86:5661-5665.

Kitamura K, Newman SL, Campagnoni CW, Verdi JM, Mohandas T, Handley VW, Campagnoni AT (1990) Expression of a novel transcript of the myelin basic protein gene. J Neurochem 54:2032-2041.

Kronquist KE, Crandall BF, Macklin WB, Campagnoni AT (1987) Expression of myelin proteins in the developing human spinal cord: cloning and sequencing of human proteolipid protein cDNA. J Neurosci Res 18:395-401.

Laemmli UK (1970) Cleavage of structural proteins during the assembly of the head of bacteriophage T4. Nature 227:680-865. 
Larsen PJ, Mikkelsen JD (1995) Functional identification of central afferent projections conveying information of acute "stress" to the hypothalamic paraventricular nucleus. J Neurosci 15:2609-2627.

Messmer B, Dreyer C (1993) Requirements for nuclear translocation and nucleolar accumulation of nucleolin of Xenopus laevis. Eur $\mathbf{J}$ Cell Biol 61:369-382.

Miskimins R, Knapp L, Dewcy MJ, Zhang X (1992) Ccll and tissucspecific expression of a heterologous gene under control of the myelin basic protein gene promoter in transgenic mice. Dev Brain Res $65: 217-221$.

Morgan JI, Cohen DA, Hempstead JL, Curran T (1987) Mapping patterns of c-fos expression in the CNS after seizure. Science 237:192-197.

Morgenstern JP, Land H (1990) Advanced mammalian gene transfer: high titer retroviral vectors with multiple drug selection markers and a complementary helper-free packaging cell line. Nucleic Acids Res 18:3587-3596.

Newman S, Kitamura K, Campagnoni AT (1987) Identification of a cDNA coding for a fifth form of myelin basic protein in mouse. Proc Natl Acad Sci USA 84:886-890.

Pribyl TM, Campagnoni CW, Kampf K, Kashima T, Handley VW, McMahon J, Campagnoni AT (1993) The human myelin basic protein gene is included within a 179-kilobase transcription unit: expression in the immune and central nervous systems. Prod Natl Acad Sci USA 90:10695-10699.

Readhead C, Popko B, Takahashi N, Shine HD, Saavedra RA, Sidman RL, Hood L (1987) Expression of a myelin basic protein gene in transgenic shiverer mice: correction of the dysmyelinating phenotype. Cell 48:703-712.

Riese J, Zeller R, Dono R (1995) Nucleo-cytoplasmic translocation and secretion of fibroblast growth factor-2 during avian gastrulation. Mech Dev 49:13-22.
Roth HJ, Kronquist KE, Kerlero de Rosbo N, Crandall BF, Campagnoni AT (1987) Evidence for the expression of four myelin basic protein variants in the developing human spinal cord through cDNA cloning. J Neurosci Res 17:321 328.

Silver P, Goodson H (1989) Nuclear protein transport. Crit Rev Biochem Mol Biol 24:419-435.

Takahashi N, Roach A, Teplow DB, Prusiner SB, Hood L (1985) Cloning and characterization of the myelin basic protein gene from mouse: one gene can encode both $14 \mathrm{kd}$ and $18.5 \mathrm{kd}$ MBPs by alternate use of exons. Cell 42:139-148.

Towbin H, Staehelin T, Gordon J (1979) Electrophoretic transfer of proteins from polyacrylamide gels to nitrocellulose sheets: procedure and some applications. Proc Natl Acad Sci USA 76:4350-4354.

Trapp BD, Moench T, Pulley M, Barbosa E, Tennekoon G, Griffin J (1987) Spatial segregation of mRNA encoding myelin-specific proteins. Prod Natl Acad Sci USA 84:7773-7777.

Verity AN, Campagnoni AT (1988) Regional expression of myelin protein genes in the developing mouse brain: in situ hybridization studies. J Neurosci Res 21:238-248.

Verity AN, Bredesen D, Vonderxcher C, Handley VW, Campagnoni AT (1993) Expression of myelin protein genes and other myelin components in an oligodendrocyte cell line conditionally immortalized with a tcmpcrature-sensitive retrovirus. J Neurochem 60:577-587.

Wetmore C, Cao YH, Pettersson RF, Olson L (1991) Brain-derived neurotrophic factor: subcellular compartmentalization and interneuronal transfer as visualized with anti-peptide antibodies. Proc Natl Acad Sci USA 88:9843-9847.

Zelenika D, Grima B, Pessac B (1993) A new family of transcripts of the myelin basic protein gene: expression in brain and in immune system. J Neurochem 60:1574-1577. 